\title{
Loop-Mediated Isothermal Amplification for the Diagnostic Detection of Meloidogyne chitwoodi and M. fallax
}

\author{
Lei Zhang and Cynthia Gleason, ${ }^{\dagger}$ Department of Plant Pathology, Washington State University, Pullman, WA 99164
}

\begin{abstract}
Meloidogyne chitwoodi is a root-knot nematode that parasitizes a broad range of plants. In the Pacific Northwest (PNW) of the United States, M. chitwoodi is a major potato pest. The nematodes infect roots and tubers; blemishes caused by the nematodes on the tubers significantly affect potato marketability. M. chitwoodi is a quarantine pathogen by many regulatory agencies, limiting potato trade opportunities when it is present. A loop-mediated isothermal amplification (LAMP) assay was developed to amplify the intergenic spacer (IGS2)-18S region of the ribosomal rDNA of $M$. chitwoodi. Using the LAMP assay, we could detect the presence of $M$. chitwoodi from infected

Washington State soil samples. The LAMP primers showed specificity for DNA from $M$. chitwoodi and the closely related species $M$. fallax. There was no cross reaction of the LAMP primers with DNA from tropical nematodes M. incognita, M. arenaria, and M. javanica, or the Northern root-knot nematode $M$. hapla. The LAMP assays can be completed within $45 \mathrm{~min}$, and they were 100 times more sensitive in nematode detection than conventional PCR. The LAMP assay will facilitate detection of potato nematodes $M$. chitwoodi and M. fallax. Knowledge of potato nematodes, particularly M. chitwoodi in PNW soils, will aid management decisions.
\end{abstract}

Root-knot nematodes (Meloidogyne spp.) are soil-borne, obligate, endoparasitic pests that cause billions of dollars in annual crop losses worldwide (Chitwood 2003; Sasser and Freckman 1987). More than 90 species of root-knot nematodes have been described (OEPP/ EPPO-Bulletin 2016). Many species of root-knot nematodes are tropical or subtropical. However, some species are adapted to more temperate climates, such as those found in the Pacific Northwest (PNW). M. hapla and M. chitwoodi are temperate-climate nematodes that are present in the potato-growing regions of the PNW (Nyczepir et al. 1984). Because $M$. chitwoodi eggs hatch at relatively low temperatures compared with $M$. hapla, M. chitwoodi populations can quickly grow within a growing season of potatoes (Charchar and Santo 2001). Therefore, $M$. chitwoodi is the predominant root-knot nematode species in the region (Elling 2013; Nyczepir et al. 1982).

Although M. chitwoodi was first identified in potatoes grown in the PNW in 1980 (O'Bannon 1982; Santo et al. 1980), the nematode was subsequently discovered to have patchy worldwide distribution. In addition to its limited distribution in the United States, M. chitwoodi is also found in Mexico, South Africa, Turkey, Argentina, and parts of Europe (the Netherlands, Portugal, Belgium, Germany) (CABI 2018; Wesemael et al. 2011). In the PNW, there are least two races of $M$. chitwoodi (race 1 and race 2) (Mojtahedi et al. 1988). These two races are indistinguishable morphologically, but they differ in host range (Mojtahedi et al. 1988; Santo and Pinkerton 1985). In 1992, a new race of $M$. chitwoodi was described in the Netherlands, but subsequent biochemical and morphological analyses determined it was a distinct species called Meloidogyne fallax (Karssen 1996; van Meggelen et al. 1994). Although M. chitwoodi and M. fallax share some common hosts, such as potatoes, they also exhibit some differences in host preference. For example, M. chitwoodi can infect corn (Zea mays), but M. fallax cannot (van Meggelen et al. 1994). Although there is a report of $M$. fallax on turfgrass in the United States, it has not been reported in field crops in the United States (Nischwitz et al. 2013).

${ }^{\dagger}$ Corresponding author: C. Gleason; E-mail: cynthia.gleason@wsu.edu

Funding: This work was partially supported by the Northwest Potato Research Consortium.

Accepted for publication 15 June 2018.

() 2019 The American Phytopathological Society
M. chitwoodi is problematic for potato growers because the nematode can infect both roots and tubers (Golden et al. 1980). The tuber infections lead to blemishes and pimple-like galls on the surface of the tubers, and these visual defects can significantly affect the potato market value (Ingham et al. 2007). In fact, if as few as 6\% of the potatoes in a field show blemishes, the entire crop can be rejected (Ingham et al. 2000). Without nematode control measures, potato fields infected with $M$. chitwoodi could have total yield loss (Elling 2013). In addition, M. chitwoodi is a quarantine pathogen in Europe, and for export markets such as Mexico, there is a near-zero tolerance for the presence of $M$. chitwoodi in potatoes (Ingham et al. 2007). Because $M$. chitwoodi is a pest with important economic impact in regions where it is found, accurate nematode identification is key for implementing nematode eradication strategies.

Because Russet potato cultivars lack resistance to M. chitwoodi, potato growers often rely on nematicides to control it. In an effort to reduce the reliance on chemical controls, a nematode resistance gene has been introduced from a wild species of potato into cultivated potato Solanum tuberosum, resulting in a breeding line called PA99N82-4 (Brown et al. 1996, 2009; Zhang et al. 2007). Interestingly, a resistance breaking isolate of $M$. chitwoodi race 1 (called pathotype Roza) was discovered in the field of the PA99N82-4 (Brown et al. 2009). Despite efforts to introduce nematode resistance into cultivated potato, the best control strategy currently for $M$. chitwoodi is proper diagnosis followed by nematode control measures, which typically includes the use of nematicides.

To determine if $M$. chitwoodi and/or other plant-parasitic nematodes are present in a field requires soil sampling and nematode identification techniques. Identification of root-knot nematode species has been traditionally based on the distinct morphological characteristics of second-stage juveniles, adult males, as well as perineal patterns of adult females (de Oliveira et al. 2011; Eisenback 1982, 1985; Seesao et al. 2017). These observational methods require considerable technical skills and experience. In recent years, many DNA-based methods using polymerase chain reaction (PCR) have been developed to provide faster and more reliable nematode diagnosis, even down to the species level (Carneiro et al. 2017). For example, PCR-based identification methods for root-knot nematode species can distinguish temperate nematodes $M$. chitwoodi, M. fallax, and/or M. hapla based on mitochondrial DNA (Powers and Harris 1993), ribosomal DNA (Petersen and Vrain 1996; Petersen et al. 1997; Wishart et al. 2002; Zeng et al. 2015; Zijlstra 1997; Zijlstra et al. 1995), or random-amplifiedpolymorphic DNA (RAPD) (Adam et al. 2005; Baum et al. 1994; Blok 
et al. 1997; Williamson et al. 1997; Zijlstra et al. 2000). The drawback to PCR-based diagnostics is that it requires relatively expensive thermocyclers and imaging systems.

In 2000, Notomi et al. developed loop-mediated isothermal application (LAMP) to amplify DNA (Notomi et al. 2000). This method took advantage of the Bst DNA polymerase with strand displacement activity to amplify large amounts of DNA in a short amount of time $(<1 \mathrm{~h})$ at single temperature, eliminating the need for the thermocycler. LAMP products can be easily seen by the naked eye using SYBR Green I or other DNA-binding dyes that visibly change color, eliminating the need for expensive imaging systems (Tomita et al. 2008). Thus, the advantages of LAMP assay make it ideal for rapid and accurate identification of various plant pathogens.

In the field of plant nematology, LAMP assays have been established for the detection of Bursaphelenchus xylophilus (Kang et al. 2015; Kikuchi et al. 2009; Meng et al. 2018), Bursaphelenchus cocophilus (Ide et al. 2017), Radopholus similis (Peng et al. 2012), Tylenchulus semipenetrans (Lin et al. 2016; Song et al. 2017), Anguina wevelli (Yu et al. 2018), and tropical root-knot nematodes $M$. incognita and M. enterolobii (Niu et al. 2011, 2012), as well as the temperate root-knot nematode $M$. hapla (Peng et al. 2017) and apple rootknot nematode M. mali (Zhou et al. 2017). We have developed a LAMP assay that can specifically identify the potato root-knot nematodes $M$. chitwoodi and $M$. fallax. Because of the importance of M. chitwoodi in the PNW, this LAMP assay will be particularly useful for detection of this nematode from infected soil samples from Washington.

\section{Materials and Methods}

Nematode isolates and DNA extraction. All three $M$. chitwoodi isolates (race 1, race 2, and Roza) were originally collected in Washington State. The initial egg inoculums were provided by Dr. Charles Brown (USDA-ARS). The $M$. hapla isolate VW9, $M$. incognita isolate VW6, $M$. javanica isolate VW4, and $M$. arenaria isolate HarA were provided by Dr. Valerie Williamson (UC-Davis). All Meloidogyne species were maintained on the susceptible tomato Solanum lycopersicum cv. Rutgers under greenhouse conditions. The identities of these isolates had been previously confirmed using speciesspecific PCR assays (Wishart et al. 2002; Zijlstra 1997). Genomic DNA of the nematodes was extracted from eggs and juveniles (J2) using the QIAamp DNA Mini kit (Qiagen, Hilden, Germany) according to the manufacturer's instructions.

LAMP primer design. The $M$. chitwoodi DNA sequence that spans the IGS2 and part of the 18S rDNA was selected as the amplification target region for LAMP primer design. The IGS2-18S rDNA sequences were downloaded from GenBank: M. chitwoodi (accession No. AJ421701), M. fallax (AJ421703), M. hapla (AJ421707), M. minor (KC262258), M. incognita (GQ395506), and M. javanica (GQ395510). Multi sequence comparison was performed using Clustal Omega (Sievers et al. 2011). The primers of LAMP were designed for the IGS2-18S rDNA specific regions of M. chitwoodi. Five primers were generated for the LAMP assay, including two outer primers (F3 and B3), one forward inner primer (FIP), one backward inner primer (BIP), and one loop backward primer (LB) (Table 1).

LAMP reactions and product detection. The LAMP reactions were performed according to the previously described protocol
(Notomi et al. 2000; Tomita et al. 2008). Briefly, a 25- $\mu$ l reaction mixture contained $1 \times$ isothermal amplification buffer, $1.4 \mathrm{mM}$ of dNTP, $1.6 \mu \mathrm{M}$ each of inner primers FIP and BIP, $0.2 \mu \mathrm{M}$ each of outer primers F3 and B3, $0.4 \mu \mathrm{M}$ of loop primer LB, $6 \mathrm{mM}$ of $\mathrm{MgSO}_{4}, 1 \mu \mathrm{l}$ of diluted genomic DNA ( 1 ng), and $8 \mathrm{U}$ of Bst 3.0 DNA polymerase (New England Biolabs, USA). To find out the optimal temperature for the LAMP assay, reactions were performed at $60-68^{\circ} \mathrm{C}$ for $45 \mathrm{~min}$. At the end, the reactions were terminated by heating them to $80^{\circ} \mathrm{C}$ for $5 \mathrm{~min}$. The products of LAMP reaction were detected using SYBR Green I (ThermoFisher Scientific, MA, USA). One $\mu l$ of 1:10 diluted SYBR Green I solution was added to the LAMP reaction tube and mixed well. After the addition of the SYBR Green I solution, LAMP reactions with amplified DNA products turned green, while the reactions without successful DNA amplification remained brown. In addition, the amplified LAMP products were monitored by $1.5 \%$ agarose gel electrophoresis that was stained with ethidium bromide and visualized under UV light. LAMP reactions were performed at least three times using at least two independent $M$. chitwoodi gDNA samples.

LAMP specificity and sensitivity analysis. To determine the analytical sensitivity of the LAMP assay, serial 10-fold dilutions of M. chitwoodi genomic DNA, with the initial concentration at $10 \mathrm{ng} / \mu \mathrm{l}$, were prepared. In addition, DNA extracts from 10-pooled $M$. chitwoodi $\mathrm{J} 2 \mathrm{~s}$, single $\mathrm{J} 2$, and serial 10 -fold dilutions of the single $\mathrm{J} 2$ DNA extract were tested by LAMP assay. The PCR was performed using the primer pair of F3/B3 designed in this study. The LAMP products were detected by both SYBR Green I staining and agarose gel electrophoresis. To determine specificity of the LAMP assay, genomic DNA purified from eggs of three isolates of $M$. chitwoodi and several other root-knot nematode species ( $M$. incognita, $M$. javanica, $M$. arenaria, and $M$. hapla) were used as template DNA. Genomic DNA of the two samples of $M$. fallax was provided by Lieven Waeyenberge, Flanders Research Institute for Agriculture, Fisheries and Food. The LAMP products were monitored by both SYBR Green I staining and agarose gel electrophoresis.

Practical evaluation of LAMP assay. To evaluate the practical application of the LAMP assay, we obtained five unlabeled soil samples from Dr. Charles Brown (USDA-ARS) in Prosser, WA. The soil samples were from pots containing tomato plants with or without nematode infections. The tomato plants were grown in 8-inch terracotta clay pots filled with sandy silt loam soil composed of $84 \%$ sand, $10 \%$ silt, and $6 \%$ clay (Brown et al. 2006). The soil was steam pasteurized before use. The tomato plants were artificially inoculated with 5,000 eggs of either $M$. chitwoodi race 1 or $M$. hapla, or they were left uninoculated as a control. After 6-8 months in the greenhouse, soil was collected from the pots and sent in unlabeled bags to Washington State University, Pullman for blind egg extraction and LAMP assays. Eggs were extracted by mixing $\sim 100 \mathrm{~g}$ of each soil sample with 0.5 liters of water and pouring the mixture over a \#200 sieve (75 micron diameter pores) and over a \#500 sieve (25 micron diameter pores). The eggs were collected off the \#500 sieve and were further purified from any remaining plant debris by sucrose flotation (van Bezooijen 2006). Genomic DNA was purified from the eggs using the QIAamp DNA Mini kit (Qiagen, Hilden, Germany) following manufacturer's instruction. One ng of DNA was subjected for LAMP and PCR assays. For the PCR assays, we used JMV1/

Table 1. Primers used for LAMP and PCR

\begin{tabular}{|c|c|c|c|c|}
\hline Primer set & $\begin{array}{l}\text { Primer } \\
\text { name }\end{array}$ & Sequence $\left(5^{\prime}-3^{\prime}\right)$ & Usage & Reference \\
\hline \multirow[t]{2}{*}{ JMV1/JMV2 } & JMV1 & GGATGGCGTGCTTTCAAC & \multirow{2}{*}{$\begin{array}{l}\text { M. chitwoodi and } \\
\text { M. fallax-specific primers }\end{array}$} & \multirow{2}{*}{$\begin{array}{l}\text { Wishart, et al } \\
(2002)\end{array}$} \\
\hline & JMV2 & TTTCCCCTTATGATGTTTACCC & & \\
\hline \multirow{2}{*}{ JMV1/JMV-Hapla } & JMV1 & GGATGGCGTGCTTTCAAC & \multirow{2}{*}{$\begin{array}{l}\text { M. hapla-specific } \\
\text { primers }\end{array}$} & \multirow{2}{*}{$\begin{array}{l}\text { Wishart, et al. } \\
(2002)\end{array}$} \\
\hline & JMV-Hapla & AAAAATCCCCTCGAAAAATCCACC & & \\
\hline \multirow[t]{5}{*}{ LAMP } & $\mathrm{F} 3$ & GAAGTCTCTCGTGTGAGAT & \multirow{5}{*}{$\begin{array}{l}\text { LAMP assay for } \\
\text { M. chitwoodi and M.fallax }\end{array}$} & \multirow[t]{5}{*}{ This study } \\
\hline & B3 & CTCGATAAATCGATTAAACTGGT & & \\
\hline & FIP & AGACACGTCGTGTCACCTATATAAAGCATAGCGGTTTGTTC & & \\
\hline & BIP & ATGAAGATATCTGGTTGATCCTGCACATGCATGGCTTAATCTTTG & & \\
\hline & LB & CTGAACTGATGTGTTCATTT & & \\
\hline
\end{tabular}


JMV2 to confirm the presence of $M$. chitwoodi and JMV1/ JMV-Hapla to confirm the presence of M. hapla (Wishart et al. 2002).

DNA was also extracted directly from nematode-inoculated soil samples and used as the template in LAMP assays. Twelve artificially inoculated soil samples were prepared by mixing $10,000 \mathrm{~J} 2 \mathrm{of}$ M. chitwoodi race 1 with $100 \mathrm{~g}$ of sandy silt loam soil. Samples of $250 \mathrm{mg}$ were taken from each and ground to a powder using a mortar and pestle. Ground soil was then used for DNA extraction using the DNeasy PowerLyzer PowerSoil Kit (Qiagen), following manufacturer's instructions. Two $\mu l$ of eluted DNA was used in the LAMP assays. The DNA extraction was also performed on $250 \mathrm{mg}$ of uninoculated soil samples; this and a no-template control were used as LAMP negative controls. Genomic DNA of $M$. chitwoodi race 1 was used as positive control in the experiment.

PCR amplifications. Reactions were performed in a $25-\mu 1$ reaction volume, including $1 \times$ standard Taq buffer, $200 \mu \mathrm{M}$ dNTP, $0.2 \mu \mathrm{M}$ primer sets of F3/B3, JMV1/JMV2, or JMV1/JMVHapla, $0.75 \mathrm{U}$ of Taq DNA polymerase (New England Biolabs, USA), and $1 \mu \mathrm{l}$ of template genomic DNA. PCR amplifications were carried out using the procedure: $95^{\circ} \mathrm{C} 2 \mathrm{~min}$, and 35 cycles of $95^{\circ} \mathrm{C}$ for $20 \mathrm{~s}$, $50^{\circ} \mathrm{C}$ for $20 \mathrm{~s}, 68^{\circ} \mathrm{C}$ for $60 \mathrm{~s}$, and a final incubation at $68^{\circ} \mathrm{C}$ for $5 \mathrm{~min}$.

\section{Results}

LAMP primer design and reaction optimization. The LAMP primers were designed based on DNA sequence differences in the intergenic spacer 2 (IGS2) region between 5S rDNA and 18S rDNA of $M$. chitwoodi (Fig. 1). The sequences of the primers F3, F2, and F1c are located in the IGS2 region, and sequences of B3, B2, and $\mathrm{B} 1 \mathrm{c}$ are located in $18 \mathrm{~S}$ region. Previous sequencing of these regions
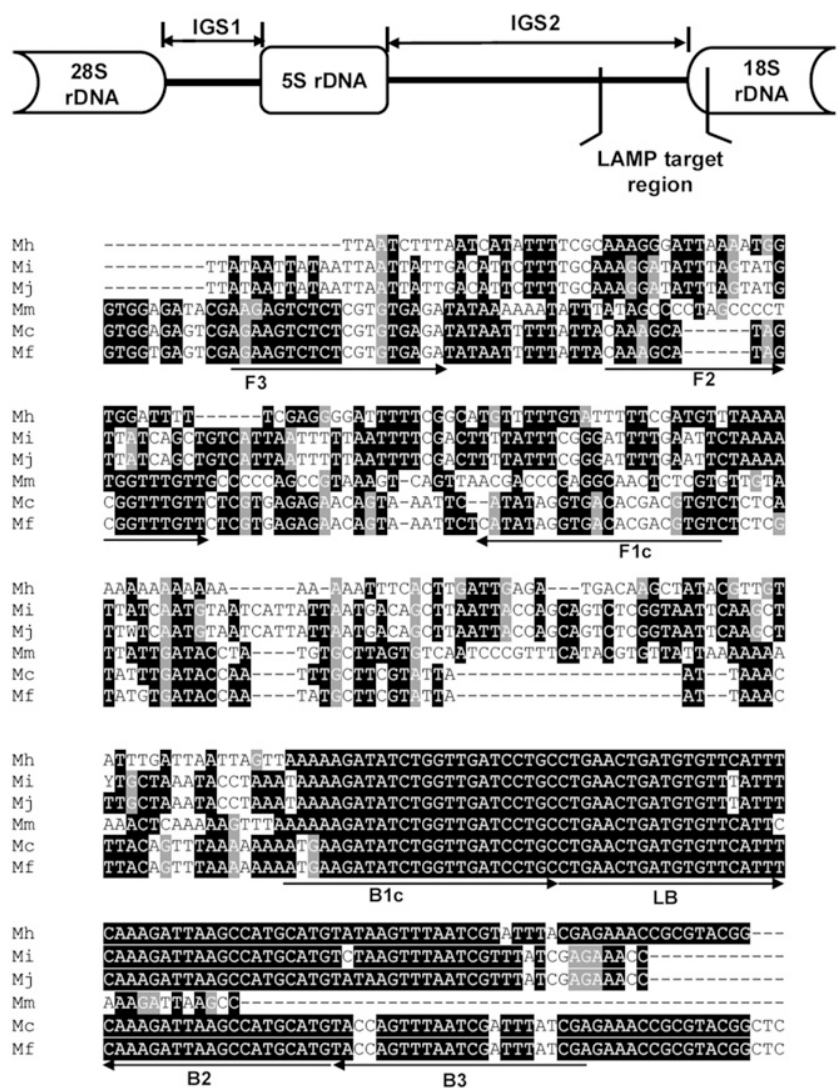

Fig. 1. Primer design for Meloidogyne chitwoodi LAMP assay based on IGS2-18S rDNA sequence. Scheme of the rDNA-IGS regions of $M$. chitwoodi is shown. Multiple alignment of the LAMP target region (partial IGS2 and partial 18S rDNA) among $M$. chitwoodi and other related root-knot nematode species is shown. The position and direction of primers are shown with arrows. Mc, Meloidogyne chitwoodi (GenBank: AJ421701); Mf, Meloidogyne fallax (GenBank: AJ421703); Mh, Meloidogyne hapla (GenBank: AJ421707); Mm, Meloidogyne minor (GenBank: KC262258); Mi, Meloidogyne incognita (GenBank: GQ395506); Mj, Meloidogyne javanica (GenBank: GQ395510). in several root-knot nematode species, including $M$. chitwoodi, M. hapla, M. incognita, and $M$. javanica, has shown that the IGS2 contains species-polymorphisms, while the $18 \mathrm{~S}$ region is conserved among the root-knot nematode species (Adam et al. 2007; Wishart et al. 2002). For the optimization of the LAMP assay using the M. chitwoodi LAMP primers, we determined the optimal reaction temperature. The reactions were performed at temperatures between $60^{\circ} \mathrm{C}$ and $68^{\circ} \mathrm{C}$ for 45 min using $1 \mathrm{ng}$ genomic DNA of $M$. chitwoodi race 1 as the template. One hallmark of successful LAMP amplification is that the LAMP products produce ladder-like banding patterns when they are separated on an agarose gel. When visualized on an agarose gel, the LAMP products from all incubation temperatures showed ladder-like banding patterns. However, the most efficient amplification and brightest banding pattern on the agarose gel occurred at an incubation temperature of $68^{\circ} \mathrm{C}$ (Fig. 2A).

An easy method for detection of LAMP products, which does not require gel electrophoresis equipment, is to add a DNA stain to the reaction mixture. After the addition of SYBR Green I stain, the M. chitwoodi LAMP products could be detected by a visual color change of the reaction from brown to green. Meanwhile, the nontemplate control (NTC) produced no ladder-like bands on the agarose gel, and the LAMP reaction was brown in color after the addition of SYBR Green I stain (Fig. 2B and C).

Analytical specificity test of LAMP assay. We wanted to determine that the LAMP primers we designed could amplify products from $M$. chitwoodi. We obtained DNA from three isolates of $M$. chitwoodi found in the PNW: race 1, race 2, and Roza. We then performed LAMP assays using genomic DNA from the three $M$. chitwoodi isolates and from DNA obtained from the tropical root-knot nematodes ( $M$. incognita, $M$. javanica, and $M$. arenaria) and the Northern root-knot nematode $M$. hapla. Both gel electrophoresis (Fig. 3A) and SYBR Green I staining of the LAMP products (Fig. 3B) showed that the LAMP primers could specifically amplify products from all three $M$. chitwoodi isolates. No products were observed from DNA templates of the 4 other Meloidogyne species: $M$. hapla, M. incognita, M. javanica, and M. arenaria (Fig. 3A and B).

To further test the specificity of the LAMP primers, we used M. fallax DNA as a template in the LAMP assay. M. fallax is a closely related nematode species to $M$. chitwoodi (Holterman et al. 2009; van Megen et al. 2009). In LAMP assays using two different DNA samples of $M$. fallax, we found amplification products visible by gel electrophoresis and by SYBR Green I staining (Fig. 3C and D). Therefore, the LAMP primers can specifically amplify from DNA of $M$. chitwoodi (race1, race 2, and race 1 Roza) and the closely related $M$. fallax.

Analytical sensitivity of LAMP assay. To compare the analytical sensitivity of LAMP assay with conventional PCR, a series of 10fold dilutions of $M$. chitwoodi race 1 genomic DNA was used as the reaction templates for both a LAMP assay and PCR. We used the primer set F3/B3 for conventional PCR. Both SYBR Green I staining and gel electrophoresis of LAMP products produced positive results up to a $10^{-5}$ dilution ( $0.1 \mathrm{pg}$ DNA) (Fig. $4 \mathrm{~A}$ and B). Meanwhile, the conventional PCR was only able to detect DNA at the dilution level of $10^{-3}$ (10 pg DNA) (Fig. 4C). Therefore, the LAMP assay is about 100 times more sensitive than the conventional PCR.

To further evaluate the analytical sensitivity of the LAMP assay, we isolated genomic DNA from $10 \mathrm{M}$. chitwoodi juveniles and a single $M$. chitwoodi juvenile. The LAMP assay was able to detect nematodes in both cases (Fig. 4D). To test the limits of detection of the LAMP assay, we made a serial 10-fold dilution of the DNA from a single juvenile to use as the template for the LAMP assays. We could positively detect $M$. chitwoodi down to a $10^{-2}$ dilution of DNA from a single nematode (Fig. 4D).

Evaluation of LAMP assay using soil samples. Because $M$. fallax has been reported once on turfgrass and is not established on crop plants in the United States (Nischwitz et al. 2013), we focused on optimizing our LAMP primers for identification of $M$. chitwoodi that is isolated from soil samples to create a useful tool for potato growers in the PNW. As a proof of concept, we wanted to determine if the LAMP assay could detect $M$. chitwoodi from artificially inoculated 
soil samples. We obtained five soil samples from the USDA Agricultural Research Service in Prosser, WA. In a blind test, we were given four samples inoculated with either M. chitwoodi or M. hapla and one uninoculated soil sample. Nematode eggs were extracted from 4 out of the 5 soil samples. The fifth sample contained no nematode eggs.
It was the uninoculated sample and used as a no-egg control. DNA was extracted from the eggs from the 4 samples, and $1 \mathrm{ng}$ of DNA from each sample was used as the template for the LAMP assays. SYBR Green I staining of LAMP products showed that M. chitwoodi was present in samples 1, 2, and 3, but not in samples 4 and 5 (no-egg control)
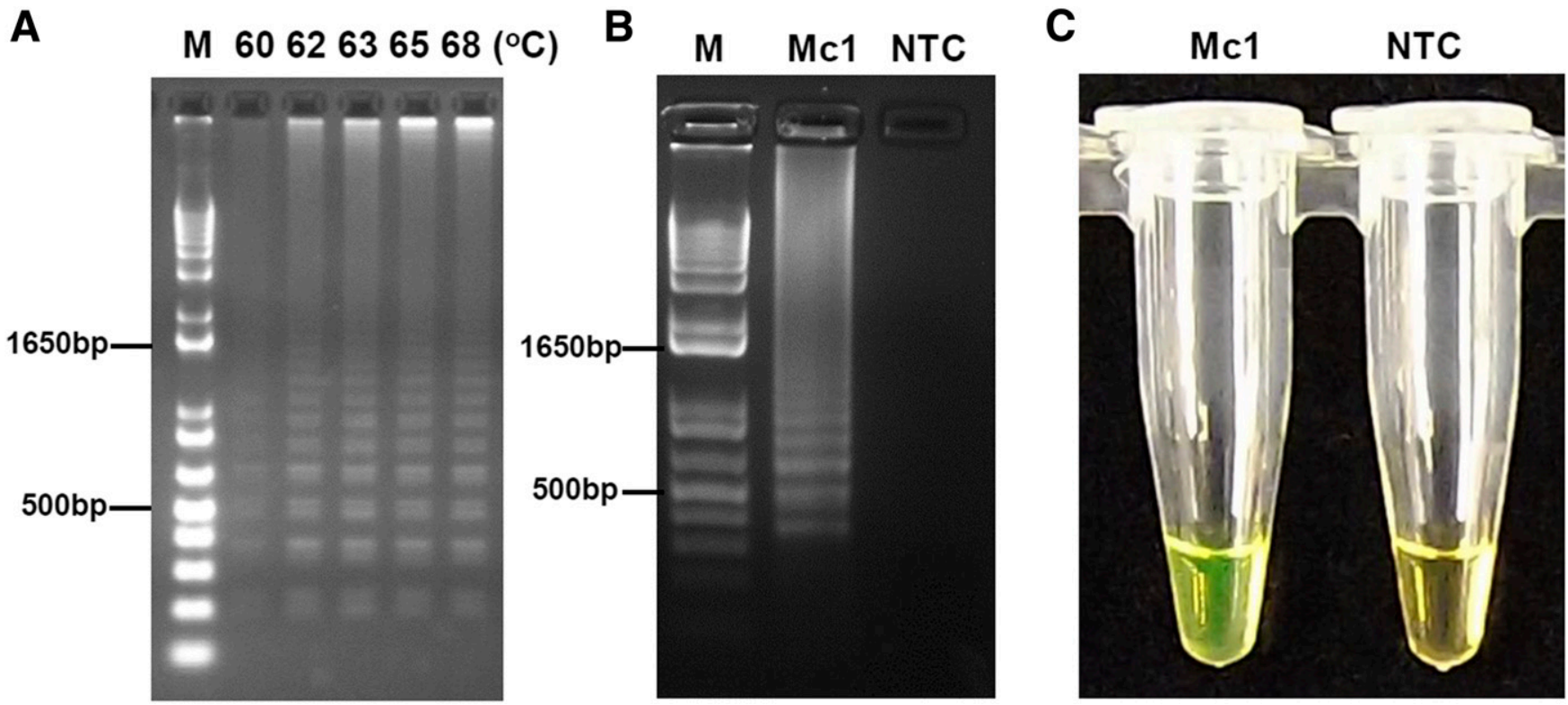

Fig. 2. LAMP reaction optimization and product detection. A, To optimize the LAMP assay temperatures, reactions were carried out at temperatures ranging from $60-68^{\circ} \mathrm{C}$ for $45 \mathrm{~min} .1 \mu \mathrm{l}$ of the LAMP reaction at each temperature was separated on a $1.5 \%$ agarose gel. The LAMP assay conducted at $68^{\circ} \mathrm{C}$ produced the brightest banding pattern on the gel. B, Agarose gel electrophoresis of $1 \mu$ l of the LAMP reaction using $1 \mathrm{ng}$ of Meloidogyne chitwoodi DNA or water (no template control, NTC). Reaction was carried out at $68^{\circ} \mathrm{C}$ for 45 min The LAMP reactions were positive for M. chitwoodi and negative for the NTC, as seen in the agarose gel and C, the reactions were stained with SYBR Green I fluorescence dye.

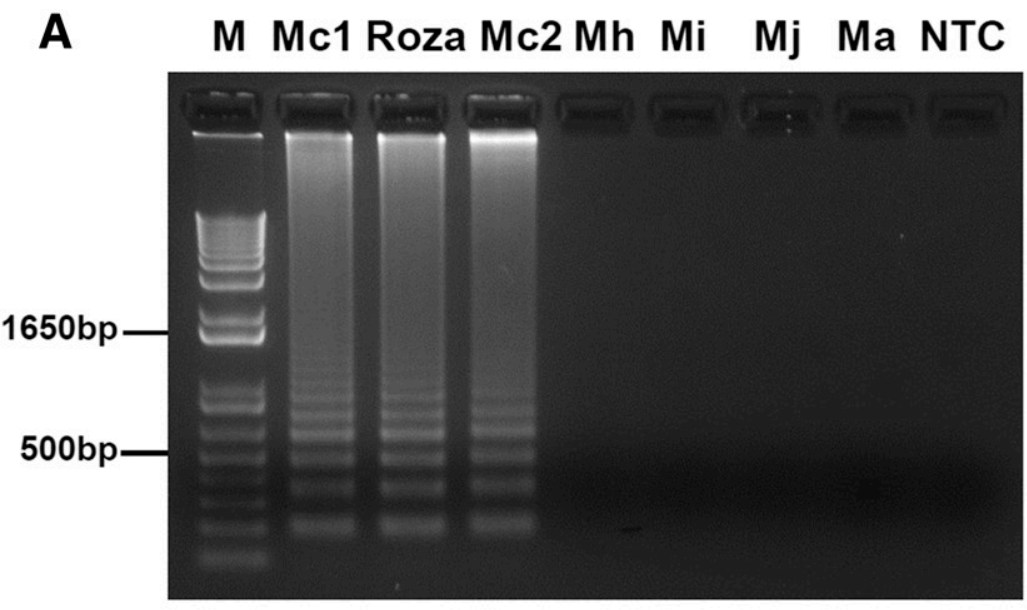

B

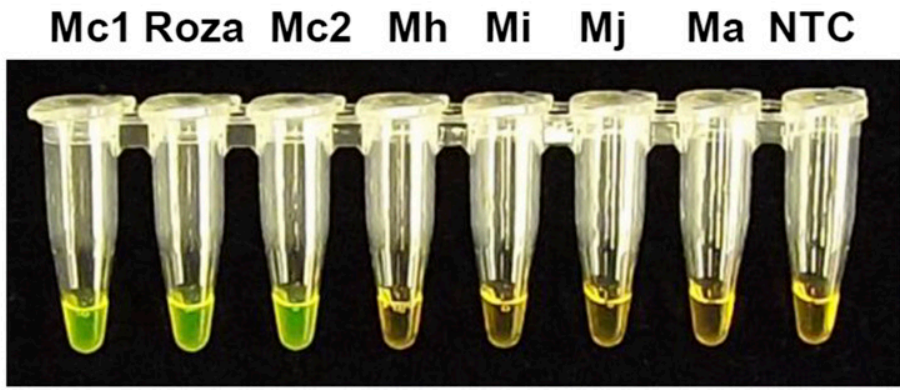

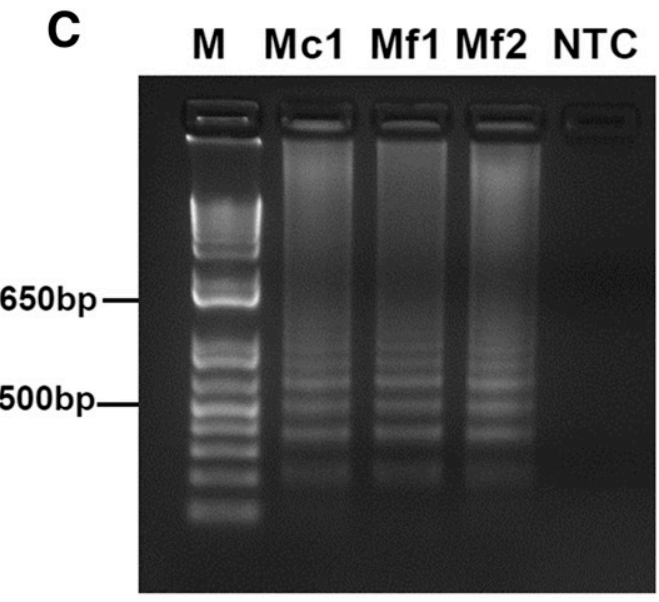

D

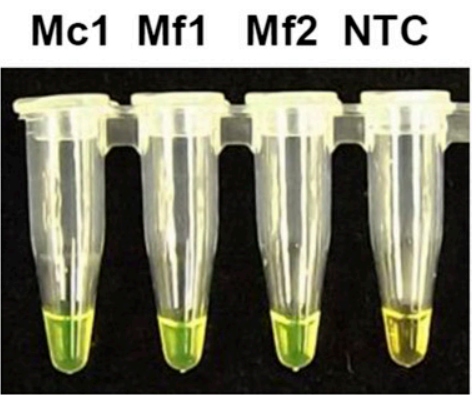

Fig. 3. Specificity test of LAMP assay. LAMP assays were performed using genomic DNA from Mc1 (Meloidogyne chitwoodi race 1), Roza (M. chitwoodi pathotype Roza), Mc2 (M. chitwoodi race 2), Mh (M. hapla VW9), Mi (M. incognita VW6), Mj (M. javanica VW4), and NTC (nontemplate control). Positive LAMP results were visualized by A, banding patterns on an agarose gel electrophoresis, and B, SYBR Green I staining of the LAMP reactions. There were positive reactions for all three M. chitwoodi isolates tested. There were no positive reactions for M. hapla (Mh), M. incognita (Mi), M. javanica (Mj), or M. arenaria (Ma) samples. When two isolates of M. fallax DNA was used as template in the LAMP assays, positive results were detected by C, agarose gel electrophoresis and D, SYBR Green I staining of the reactions. 
(Fig. 5A). To confirm that the eggs in samples 1-3 were M. chitwoodi, the DNA was used as a template for PCR using the primer set JMV1/ JMV2 (Wishart et al. 2002). To determine the identity of the eggs in sample 4, a PCR was performed using the primer set JMV1/JMVHapla, which had been previously shown to specifically amplify a 440-bp band from M. hapla DNA (Wishart et al. 2002). The PCR results show that samples 1-3 were $M$. chitwoodi and sample 4 contained $M$. hapla eggs (Fig. 5B and C). Hence, the LAMP assay is able to specifically detect $M$. chitwoodi present in soil samples.

To further demonstrate the utility of the LAMP assay, we inoculated 12 soil samples with $M$. chitwoodi juveniles and then directly extracted DNA from each soil sample. The LAMP assay was able to detect the presence of $M$. chitwoodi in all 12 DNA samples extracted directly from the nematode-inoculated soils (Fig. 5D). Thus, the LAMP assay can detect nematode DNA from soil DNA extracts. This eliminates the need to first isolate the nematodes from the soil before the DNA extraction step.

\section{Discussion}

Because of its capability of DNA amplification at isothermal conditions with high sensitivity and efficiency, the LAMP assay serves as a useful tool for plant-parasitic nematode identification. In this

A

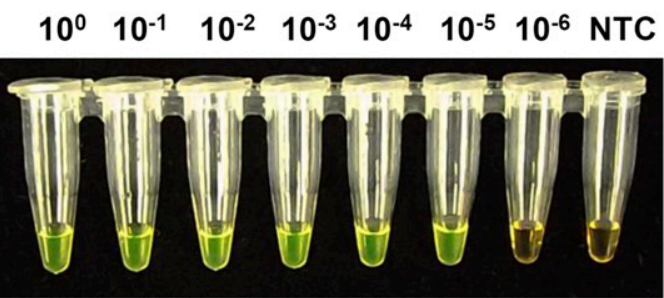

B

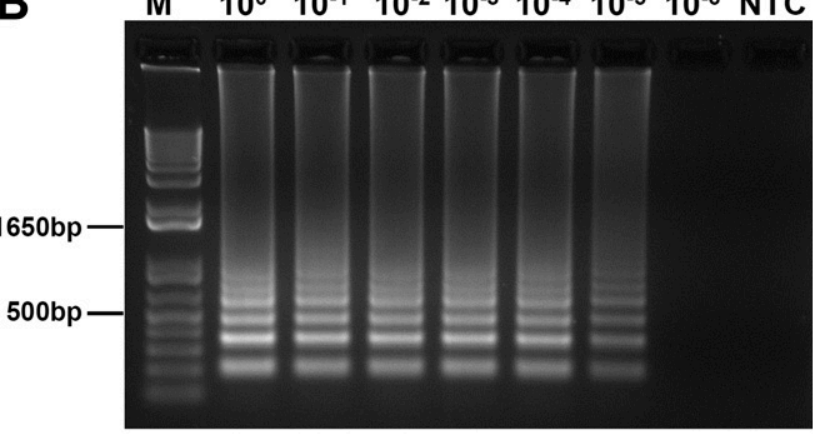

C
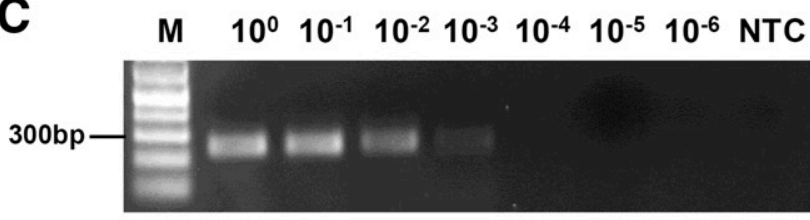

D

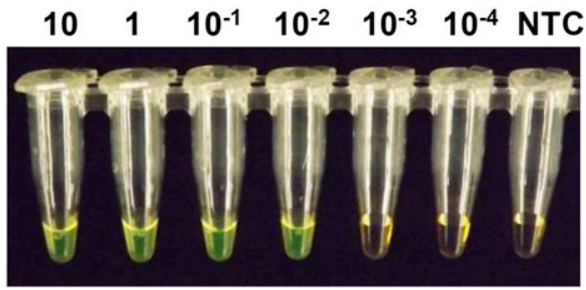

Fig. 4. Sensitivity test of LAMP assay compared with conventional PCR. A, SYBR Green I staining and $\mathbf{B}$, agarose gel electrophoresis of LAMP products indicate that the LAMP assay can detect Meloidogyne chitwoodi DNA that has been diluted from 100 (10 ng DNA) to $10^{-5}$ (0.1 pg DNA). C, PCR can detect M. chitwoodi DNA that has been diluted from $100\left(10 \mathrm{ng}\right.$ DNA) to $10^{-3}(10 \mathrm{pg}$ DNA). D, SYBR Green I staining of LAMP reactions showed that the assay detects $M$. chitwoodi DNA extracted from $10 \mathrm{~J} 2$, one $\mathrm{J} 2$, and up to a 100 -fold dilution of DNA extracted from single $\mathrm{J} 2$. NTC, no template control. study, we developed a LAMP assay to detect potato root-knot nematodes $M$. chitwoodi and M. fallax. The LAMP primers were designed for the IGS2-18S region of $M$. chitwoodi rDNA. Our LAMP primers amplified products from three $M$. chitwoodi isolates found in the western United States: race1, Roza, and race 2. Although these isolates are nearly morphologically indistinguishable, race 1 and race 2 differ in their ability to infect carrot and alfalfa, and Roza overcomes the natural resistance found in the wild potato species Solanum bulbocastanum (Brown et al. 2009; Humphreys-Pereira and Elling 12013). Our results showed that our LAMP primers are stable across the different $M$. chitwoodi isolates; and thus, the LAMP assay is a reliable identification tool regardless of $M$. chitwoodi race.

Interestingly, our LAMP assay showed specificity for both $M$. chitwoodi and its close relative $M$. fallax. M. fallax is referred to as
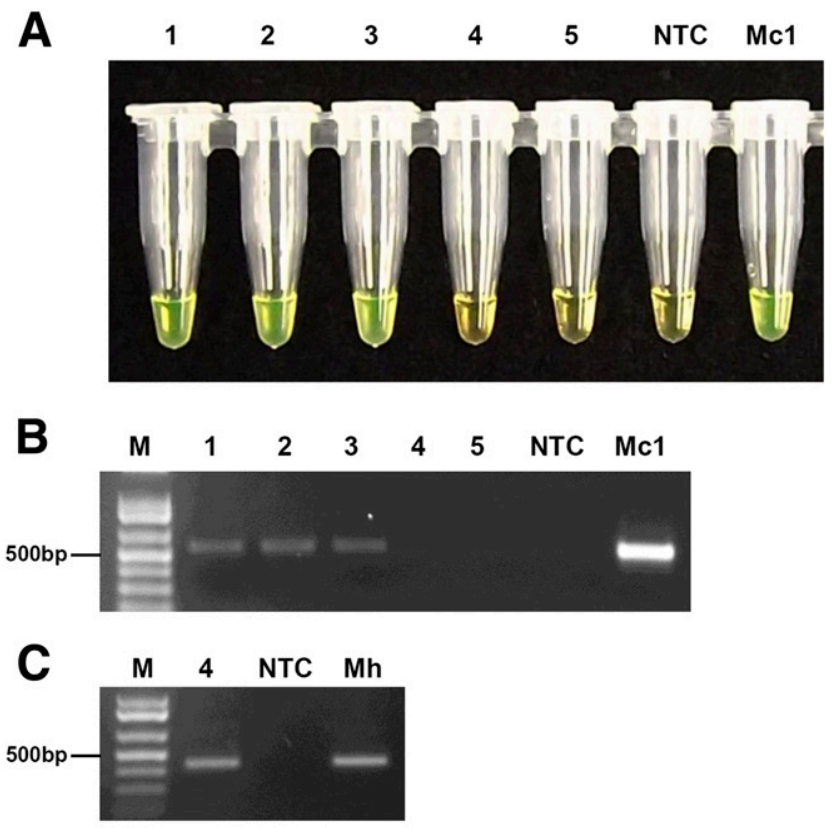

D

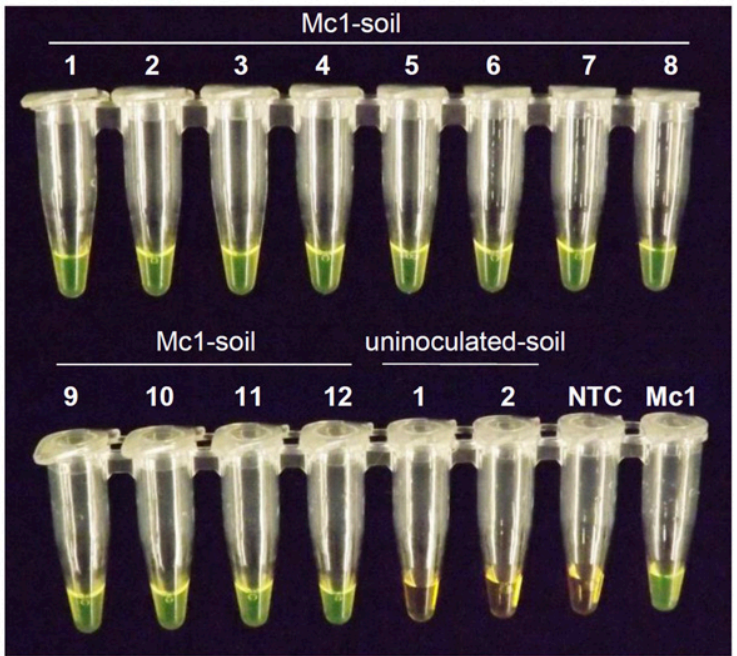

Fig. 5. Evaluation of LAMP assay using soil samples. A, LAMP assays on DNA isolated from nematode eggs extracted from four nematode infested soil samples (1-4) and soil from an uninoculated pot (5). As a positive control, $1 \mathrm{ng}$ genomic DNA of Meloidogyne chitwoodi race 1 was used as a template (Mc1) in the LAMP assay and PCR. B, PCR using JMV1/JMV2 primers confirmed that the eggs in soil samples 1-3 were $M$. chitwoodi. C, PCR using $M$. hapla specific primers JMV1/JMV-Hapla confirmed that the eggs present in soil sample 4 were from M. hapla. Lane Mh indicates a PCR using $1 \mathrm{ng}$ genomic DNA from M. hapla isolate VW9. NTC, no template control. D, DNA was extracted from M. chitwoodi J2 inoculated soil samples (Mc1-soil), or uninoculated-soil samples. SYBR Green I staining of LAMP products showed M. chitwoodi in all 12 Mc1-soil samples. The LAMP reactions from two uninoculated-soil samples, NTC and Mc1 genomic DNA, were used as controls. 
the "false Columbia root-knot nematode," and it was previously known as M. chitwoodi (Baexem) B-type (van Meggelen et al. 1994). Additional morphological and biochemical studies determined that M. fallax and M. chitwoodi are different species (Karssen 1995; Zijlstra 1997). Currently, M. fallax is primarily found in parts of Europe, Australia, and South America (CABI/EPPO 2017). Although in a recent report, $M$. fallax was reported in turf grass on a California golf course (McClure et al. 2012), there are no reports of M. fallax on crops in the United States, and it is not known to be present in Washington State. Since M. fallax has not been reported in crop fields in the PNW, a positive LAMP assay using our primers would most likely indicate the presence of $M$. chitwoodi. If there were a positive result in the LAMP assay, concerned parties could distinguish the two species by PCR amplification of the rDNA intergenic spacer (IGS) region (Petersen and Vrain 1996; Petersen et al. 1997; Wishart et al. 2002) or by looking at the restriction fragment length polymorphisms (RFLPs) of the ITS of rDNA (Zijlstra 1997). The drawback to these techniques is that they require specialized equipment, such as a thermocycler and electrophoresis unit. Therefore, we propose that our LAMP assay can be a quick, easy assessment of potato root-knot nematodes in samples, and if necessary, a positive sample can be further examined using techniques that are more sophisticated.

In summary, our study has developed a sensitive and fast LAMP assay that positively detects $M$. chitwoodi and M. fallax, but it could not amplify products from three tropical root-knot nematode species (M. incognita, $M$. arenaria, and $M$. javanica) or temperate root-knot nematode $M$. hapla. The LAMP assay is more sensitive than conventional PCR, and it does not require complicated equipment. Therefore, it can be used as a simple tool for nematode identification with future potential for in-field surveys.

\section{Acknowledgments}

We thank Dr. Chuck Brown and Launa Hamlin (USDA-ARS, Prosser Research and Extension Center, Washington) for $M$ chitwoodi isolates and infected soil samples. We also thank Dr. Valerie Williamson (UC Davis) for the M. incognita, M. javanica, M. arenaria, and M. hapla populations, and Dr. Lieven Waeyenberge of the Flanders Research Institute for Agriculture, Fisheries and Food for kindly providing the M. fallax DNA samples.

\section{Literature Cited}

Adam, M. A. M., Phillips, M. S., and Blok, V. C. 2005. Identification of Meloidogyne spp. from North East Libya and comparison of their inter- and intra-specific genetic variation using RAPDs. Nematology 7:599-609.

Adam, M. A. M., Phillips, M. S., and Blok, V. C. 2007. Molecular diagnostic key for identification of single juveniles of seven common and economically important species of root-knot nematode (Meloidogyne spp.). Plant Pathol. 56:190-197.

Baum, T. J., Gresshoff, P. M., Lewis, S. A., and Dean, R. A. 1994. Characterization and phylogenetic analysis of four root-knot nematode species using DNA amplification fingerprinting and automated polyacrylamide gel electrophoresis. Mol. Plant-Microbe Interact. 7:39-47.

Blok, V. C., Phillips, M. S., and Fargette, M. 1997. Comparison of sequences from the ribosomal DNA intergenic region of Meloidogyne mayaguensis and other major tropical root-knot nematodes. J. Nematol. 29:16-22.

Brown, C. R., Mojtahedi, H., James, S., Novy, R. G., and Love, S. 2006. Development and evaluation of potato breeding lines with introgressed resistance to Columbia Root-Knot Nematode (Meloidogyne chitwoodi). Am. J. Potato Res. 83:1-8.

Brown, C. R., Mojtahedi, H., Zhang, L. H., and Riga, E. 2009. Independent resistant reactions expressed in root and tuber of potato breeding lines with introgressed resistance to Meloidogyne chitwoodi. Phytopathology 99:1085-1089.

Brown, C. R., Yang, C.-P., Mojtahedi, H., Santo, G. S., and Masuelli, R. 1996. RFLP analysis of resistance to Columbia root-knot nematode derived from Solanum bulbocastanum in a BC2 population. Theor. Appl. Genet. 92:572-576.

CABI. 2018. Meloidogyne chitwoodi. In: Invasive Species Compendium. CAB International, Wallingford, UK. http://www.cabi.org/isc.

CABI/EPPO. 2017. Meloidogyne fallax (false Columbia root-knot nematode). In: Invasive Species Compendium. CAB International, Wallingford, UK. https:// www.cabi.org/isc.

Carneiro, R. M. D. G., Lima, F. S. O., and Correia, V. R. 2017. Methods and tools currently used for the identification of plant parasitic nematodes. Pages 19-35 in: Nematology - Concepts, Diagnosis and Control. M. M. Shah and M. Mahamood, eds. InTech, Rijeka.

Charchar, J. M., and Santo, G. S. 2001. Effect of temperature on the embryogenic development and hatching of Meloidogyne chitwoodi races 1 and 2 and M. hapla. Nematol. Bras. 25:71-77.
Chitwood, D. J. 2003. Research on plant-parasitic nematode biology conducted by the United States Department of Agriculture-Agricultural Research Service. Pest Manag. Sci. 59:748-753.

de Oliveira, C. M. G., Monteiro, A. R., and Blok, V. C. 2011. Morphological and molecular diagnostics for plant-parasitic nematodes: Working together to get the identification done. Trop. Plant Pathol. 36:65-73.

Eisenback, J. D. 1982. Morphological comparison of head shape and stylet morphology of second-stage juveniles of Meloidogyne species. J. Nematol. 14:339-343.

Eisenback, J. D. 1985. Diagnostic characters useful in the identification of the four most common species of root-knot nematodes (Meloidogyne spp.). Pages 95-112 in: An Advanced Treatise on Meloidogyne, 1 Biology and Control. J. N. Sasser and C. C. Carter, ed. North Carolina State University, Raleigh, USA.

Elling, A. A. 2013. Major emerging problems with minor Meloidogyne species. Phytopathology 103:1092-1102.

Golden, A. M., Obannon, J. H., Santo, G. S., and Finley, A. M. 1980. Description and SEM observations of Meloidogyne chitwoodi N-Sp (Meloidogynidae), a root-knot nematode on potato in the Pacific Northwest. J. Nematol. 12:319-327.

Holterman, M., Karssen, G., van den Elsen, S., van Megen, H., Bakker, J., and Helder, J. 2009. Small subunit rDNA-based phylogeny of the Tylenchida sheds light on relationships among some high-impact plant-parasitic nematodes and the evolution of plant feeding. Phytopathology 99:227-235.

Humphreys-Pereira, D. A., and Elling, A. A. 2013. Intraspecific variability and genetic structure in Meloidogyne chitwoodi from the USA. Nematology 15: 315-327.

Ide, T., Kanzaki, N., Parra Giraldo, P. P., and Giblin-Davis, R. M. 2017. Loopmediated isothermal amplification (LAMP) for detection of the red ring nematode. Nematology 19:559-565.

Ingham, R. E., Hamm, P. B., Baune, M., David, N. L., and Wade, N. M. 2007. Control of Meloidogyne chitwoodi in potato with shank-injected metam sodium and other nematicides. J. Nematol. 39:161-168.

Ingham, R. E., Hamm, P. B., Williams, R. E., and Swanson, W. H. 2000. Control of Meloidogyne chitwoodi in potato with fumigant and nonfumigant nematicides. J. Nematol. 32:556-565.

Kang, J. S., Kim, A. Y., Han, H. R., Moon, Y. S., and Koh, Y. H. 2015 Development of two alternative Loop-mediated isothermal amplification tools for detecting pathogenic pine wood nematodes. For. Pathol. 45:127-133.

Karssen, G. 1995. Morphological and biochemical differentiation in Meloidogyne chitwoodi populations in the Netherlands. Nematologica 41:314-315.

Karssen, G. 1996. Description of Meloidogyne fallax n. sp. (Nematoda: Heteroderidae), a root-knot nematode from The Netherlands. Fundam. Appl. Nematol. 19:593-599.

Kikuchi, T., Aikawa, T., Oeda, Y., Karim, N., and Kanzaki, N. 2009. A rapid and precise diagnostic method for detecting the Pinewood nematode Bursaphelenchus xylophilus by loop-mediated isothermal amplification. Phytopathology 99: 1365-1369.

Lin, B., Wang, H., Zhuo, K., and Liao, J. 2016. Loop-mediated isothermal amplification for the detection of Tylenchulus semipenetrans in soil. Plant Dis. 100:877-883.

McClure, M. A., Nischwitz, C., Skantar, A. M., Schmitt, M. E., and Subbotin, S. A 2012. Root-knot nematodes in golf course greens of the Western United States. Plant Dis. 96:635-647.

Meng, F., Wang, X., Wang, L., Gou, D., Liu, H., Wang, Y., and Piao, C. 2018. A loop-mediated isothermal amplification-based method for detecting Bursaphelenchus xylophilus from Monochamus alternatus. For. Pathol. 48:e12404.

Mojtahedi, H., Santo, G. S., and Wilson, J. H. 1988. Host tests to differentiate Meloidogyne chitwoodi races 1 and 2 and M. hapla 1. J. Nematol. 20:468-473.

Nischwitz, C., Skantar, A., Handoo, Z. A., Hult, M. N., Schmitt, M. E., and McClure, M. A. 2013. Occurrence of Meloidogyne fallax in North America, and molecular characterization of M. fallax and M. minor from U.S. golf course greens. Plant Dis. 97:1424-1430.

Niu, J. H., Guo, Q. X., Jian, H., Chen, C. L., Yang, D., Liu, Q., and Guo, Y. D 2011. Rapid detection of Meloidogyne spp. by LAMP assay in soil and roots. Crop Prot. 30:1063-1069.

Niu, J. H., Jian, H., Guo, Q. X., Chen, C. L., Wang, X. Y., Liu, Q., and Guo, Y. D. 2012. Evaluation of loop-mediated isothermal amplification (LAMP) assays based on 5S rDNA-IGS2 regions for detecting Meloidogyne enterolobii. Plant Pathol. 61:809-819.

Notomi, T., Okayama, H., Masubuchi, H., Yonekawa, T., Watanabe, K., Amino, N., and Hase, T. 2000. Loop-mediated isothermal amplification of DNA. Nucleic Acids Res. 28:e63.

Nyczepir, A. P., Inserra, R. N., O'Bannon, J. H., and Santo, G. S. 1984. Influence of Meloidogyne chitwoodi and M. hapla on wheat growth. J. Nematol. 16:162-165.

Nyczepir, A. P., O’Bannon, J. H., Santo, G. S., and Finley, A. M. 1982. Incidence and distinguishing characteristics of Meloidogyne chitwoodi and M. hapla in potato from the Northwestern United States. J. Nematol. 14:347-353.

O'Bannon, J. H. 1982. Host range of the Columbia root-knot nematode. Plant Dis. 66:1045-1048

OEPP/EPPO Bulletin. 2016. PM 7/41 (3) Meloidogyne chitwoodi and Meloidogyne fallax. EPPO Bull. 46:171-189.

Peng, H., Long, H., Huang, W., Liu, J., Cui, J., Kong, L., Hu, X., Gu, J., and Peng, D. 2017. Rapid, simple and direct detection of Meloidogyne hapla from 
infected root galls using loop-mediated isothermal amplification combined with FTA technology. Sci. Rep. 7:44853.

Peng, H., Peng, D. L., Hu, X. Q., He, X. F., Wang, Q., Huang, W. K., and He, W. T. 2012. Loop-mediated isothermal amplification for rapid and precise detection of the burrowing nematode, Radopholus similis, directly from diseased plant tissues. Nematology 14:977-986.

Petersen, D. J., and Vrain, T. C. 1996. Rapid identification of Meloidogyne chitwoodi, M. hapla, and M. fallax using PCR primers to amplify their ribosomal intergenic spacer. Fundam. Appl. Nematol. 6:601-605.

Petersen, D. J., Zijlstra, C., Wishart, J., Blok, V., and Vrain, T. C. 1997. Specific probes efficiently distinguish root-knot nematode species using signature sequences in the ribosomal intergenic spacer. Fundam. Appl. Nematol. 20:619-626.

Powers, T. O., and Harris, T. S. 1993. A polymerase chain reaction method for identification of five major Meloidogyne species. J. Nematol. 25:1-6.

Santo, G. S., O'Bannon, J. H., Finley, A. M., and Golden, A. M. 1980. Occurrence and host range of a new root-knot nematode (Meloidogyne chitwoodi) in the Pacific Northwest. Plant Dis. 64:951-952.

Santo, G. S., and Pinkerton, J. N. 1985. A second race of Meloidogyne chitwoodi discovered in Washington. Plant Dis. 69:361.

Sasser, J. N., and Freckman, D. W. 1987. A world perspective on nematology: The role of society. Pages 7-14 in: Vistas on Nematology: A Commemoration of the Twenty-fifth Anniversary of the Society of Nematologist. J. A. Veech and D. W. Dickson, eds. Society of Nematologists, Lakeland, FL.

Seesao, Y., Gay, M., Merlin, S., Viscogliosi, E., Aliouat-Denis, C. M., and Audebert, C. 2017. A review of methods for nematode identification. J. Microbiol. Methods 138:37-49.

Sievers, F., Wilm, A., Dineen, D., Gibson, T. J., Karplus, K., Li, W. Z., Lopez, R., McWilliam, H., Remmert, M., Soding, J., Thompson, J. D., and Higgins, D. G. 2011. Fast, scalable generation of high-quality protein multiple sequence alignments using Clustal Omega. Mol. Syst. Biol. 7:539.

Song, Z.-Q., Cheng, J.-E., Cheng, F.-X., Zhang, D.-Y., and Liu, Y. 2017. Development and evaluation of loop-mediated isothermal amplification assay for rapid detection of Tylenchulus semipenetrans using DNA extracted from soil. Plant Pathol. J. 33:184-192.

Tomita, N., Mori, Y., Kanda, H., and Notomi, T. 2008. Loop-mediated isothermal amplification (LAMP) of gene sequences and simple visual detection of products. Nat. Protoc. 3:877-882.

van Bezooijen, J. 2006. Methods and Techniques for Nematology. Wageningen University, Wageningen, Netherlands. van Megen, H., van den Elsen, S., Holtermann, M., Karssen, G., Mooyman, P., Bongers, T., Holovachov, O., Bakker, J., and Helder, J. 2009. A phylogenetic tree of nematodes based on about 1200 full-length small subunit ribosomal DNA sequences. Nematology 11:927-950.

van Meggelen, J. C., Karssen, G., Janssen, G. J. W., Verkerk-Bakker, B., and Janssen, R. 1994. A new race of Meloidogyne chitwoodi Golden, O'Bannon, Santo \& Finley, 1980? Fundam. Appl. Nematol. 17:93-96.

Wesemael, W. M. L., Viaene, N., and Moens, M. 2011. Root-knot nematodes (Meloidogyne spp.) in Europe. Nematology 13:3-16.

Williamson, V. M., Caswell-Chen, E. P., Westerdahl, B. B., Wu, F. F., and Caryl G. 1997. A PCR assay to identify and distinguish single juveniles of Meloidogyne hapla and M. chitwoodi. J. Nematol. 29:9-15.

Wishart, J., Phillips, M. S., and Blok, V. C. 2002. Ribosomal intergenic spacer: A polymerase chain reaction diagnostic for Meloidogyne chitwoodi, M. fallax, and M. hapla. Phytopathology 92:884-892.

Yu, L., Song, S.-Y., Yu, C., Qi, L., Yu, Z., Jiao, B., and Yang, J. 2018. A loop mediated isothermal amplification (LAMP) assay for rapid and reliable detection of Anguina wevelli, a grass parasitic nematode. Eur. J. Plant Pathol. 150:725-734.

Zeng, Y., Ye, W., Kerns, J., Tredway, L., Martin, S., and Martin, M. 2015. Molecular characterization and phylogenetic relationships of plant-parasitic nematodes associated with turfgrasses in North Carolina and South Carolina, United States. Plant Dis. 99:982-993.

Zhang, L. H., Mojtahedi, H., Kuang, H., Baker, B., and Brown, C. R. 2007. Marker-assisted selection of Columbia root-knot nematode resistance introgressed from Solanum bulbocastanum. Crop Sci. 47:2021-2026.

Zhou, Q., Cai, Y., Gu, J., Wang, X., and Chen, J. 2017. Rapid and sensitive detection of Meloidogyne mali by loop-mediated isothermal amplification combined with a lateral flow dipstick. Eur. J. Plant Pathol. 148:755-769.

Zijlstra, C. 1997. A fast PCR assay to identify Meloidogyne hapla, M. chitwoodi, and $M$. fallax, and to sensitively differentiate them from each other and from M. incognita in mixtures. Fundam. Appl. Nematol. 20:505-511.

Zijlstra, C., Donkers-Venne, D. T. H. M., and Fargette, M. 2000. Identification of Meloidogyne incognita, $M$. javanica and $M$. arenaria using sequence characterised amplified region (SCAR) based PCR assays. Nematology 2: 847-853.

Zijlstra, C., Lever, A. E. M., Uenk, B. J., and Van Silfhout, C. H. 1995. Differences between ITS regions of isolates of root-knot nematodes Meloidogyne hapla and M. chitwoodi. Phytopathology 85:1231-1237. 